\title{
Operation Strategy as a Competitive Advantage in Hotel Industry
}

\author{
Tan Seng Teck ${ }^{1}$, Nanthakumar Karuppiah ${ }^{2}$ \\ ${ }^{1}$ Senior Lecturer, Faculty of Business, Communication and Law (FOBCAL), INTI International University, \\ Malaysia \\ ${ }^{2}$ Senior Lecturer, University of Hertfordshire Centre, INTI International College, Malaysia \\ Correspondence: Tan Seng Teck, Faculty of Business, Communication and Law (FOBCAL), INTI International \\ University, Malaysia.
}

Received: December 16, 2019

Accepted: January 6, 2020

Online Published: January 16, 2020

doi:10.5539/ibr.v13n2p35

URL: https://doi.org/10.5539/ibr.v13n2p35

\begin{abstract}
This paper explores the role of operation management in Hotel industry in Malaysia. It explains the contributions of operation management as a strategic tool for attaining customers' satisfaction as well as sustainability. It reveals some of the examples of hoteliers that have thrived on these concepts.
\end{abstract}

Keywords: operation management, strategy, competitive advantage

\section{An Introduction to Operations Management}

Operations management $(\mathrm{OM})$ is a widely studied subject. Literatures are plentiful. The underlying values of $\mathrm{OM}$ as a genre in management is rich and deep. Heizer et. al (1999) defined operation management (hereinafter referred to as $\mathrm{OM}$ ) as the procedures and processes that change raw materials and input into outputs or products and services. OM has a long history from the eighteenth century since the days of Adam Smith discovered the advantages of division of labour fortified by Frederick Taylor's scientific management theories. Since then, OM has progressed a long way from scheduling of employee's work and mechanization to the advents of total quality management (see Deming and Juran, 1980).

However, earlier literatures on OM are very technical. Effective divisions of labour, just in time (JIT) and quality control seem to permeate the literatures in the earlier days. Classical OM writings are distinctively scientific. They are concerned with practical rather than strategy issues. Prior literatures on OM lacked a grounded theory (Schmenner and Swink 1998). There is deficit of theoretical basis, as earlier literatures addressed mainly operational and practical challenges within a business firm. There is also a shortage of a strategic rigor. Others accused these literatures as multidisciplinary, perceived to be merely subsets from more grounded management theories (Melnyk \& Handfield 1998). As Westbrook (1994) mentioned "operation management remains a subject with a poor conceptual base, and theory building through empirical research methods will become an increasingly important strand of operation management research activity in future years". Whilst some exalt the rich multidisciplinary context in OM theories (Van de Ven, 1989) others argue OM falls short of contributing to a specific management knowledge.

However, these criticisms are retreating. Modern studies on OM gained stronger footing in management. OM is now a source of competitive advantage. The nexus between OM and strategy as vindicated. Slack et al (2004) said: "operations strategy concerns the pattern of strategic decisions and actions which set the role, objectives and activities of operations". Clearly, modern writings on OM are no longer limited to practical and technical concerns but have since assumed more strategic roles. However, how does the alignment of OM with corporate strategy provide a competitive advantage to a firm?

A strategy concerns how a business firm can position itself within a given market segment in the end. This involves strategic positioning, unique branding and how the market segment can be defended effectively amidst stern competitions. The role of operation is to translate and organisation vision and mission on ground (Slack et al., 2004). Operational strategy in hotel industry linked to the agenda of differentiating the hotel in terms of operational excellence benchmarked against the rivalries and the ability to meet the demands of the customers as well as addressing pressing issues in the macro environment.

This paper examines the values of OM as a strategy for hotel industry. One of the most essential issue facing 
hotel industry is increasing internal rivalry and competition both locally and those furnished globally. There is a dire need for hotel industry to create a competitive advantage and a difference amidst this competitive environment. They need to create a difference through three differentials that is through (a) connectivity, (b) speed of business and (c) intangibility, which is to boost repute and brand image. This paper is to examine how $\mathrm{OM}$ can offer and furnish a sustainable strategy for hotels within the industry to thrive against competitors and to survive in the cutthroat environment. This paper is structured in three sections. Firstly, to examine the emerging challenges amidst the hotel industry in Malaysia, secondly to examine the emerging role of OM as a strategy contribution to the industry and thirdly to examine some challenges and barriers that hoteliers faced in the modern $21^{\text {st }}$ century hotel and OM issues.

\section{The Emerging Challenges in Hotel Industry}

Tourism and hospitality industry is an old industry. It began in the $20^{\text {th }}$ century modestly when people started visiting friends in other states. Currently, tourism and hospitality is one of the most profitable industry. According to Weaver and Lauton (2008), in the year 2007, the tourism industry generated approximately 300 million employment opportunities and approximately 980 million overseas and local destinations worldwide. Tourism and hospitality is developing fast particularly in developing states. Muhamad and Henderson (2003) argued that developing countries ought to take advantage of this development as it provides and fuels strong economic growth for the country and attracts foreign direct investments. It also increases the cycle of globalization within the country.

In Malaysia, tourism and hoteling is fast becoming a major contributor of the Malaysian GDP and a major foreign exchange almost equalling export of manufactured products (The 2009 Malaysian Budget). Poon and Low (2005) argued that the income from this industry will surpass the income by manufacturing industry and the growth of tourism and hoteling spikes an increase in surrounding industries such as F\&B and entertainment industries.

In 2008, tourism and hoteling have generated RM130 million in 2009 and the average expansion and growth rate of this industry is approximately $8 \%$ per year. In 2007 alone, the industry has generated more than 980,000 jobs and represents approximately 5\% of the total GDP in Malaysia (www.motour.gov.my). The $9^{\text {th }}$ Malaysian plan has set much allocations of budgets to increase tourism in Malaysia. This includes unconventional tourism and hoteling such as home stays, budget inns, boutique hotels and of course, the larger star rated hotels. Other more innovative measures include health tourism for traditional and alternative medication, which was established together as a joint venture between the Ministry of Health and Ministry of Tourism. Other forms of tourism include the promotion of green tourism and the establishment of Green tourism and the Green Hotel rating has promoted the industry locally and also attracted larger hotel name and brands from overseas (Tan, 2010).

Because of rapid tourism growth, the Malaysian hotel industry has been growing too. This is witnessed through the growing number of hotels established in Malaysia as well as the increase of rooms provided by these facilities. In year 200, there were only 1500 rooms whereas this number increased to 2500 in the year 2000. In 2015, the number is recorded at 4000 rooms (a rate for star rated hotels in Malaysia) (Nor Sadir Salleh et al., 2016). This is especially in high tourists' traffic and popular spots like Redang, Langkawi and many other inland destinations like Malacca and Penang.

The growth of the hotel industry in Malaysia is higher as compared to neighbouring countries. This can be assessed through the higher occupational rates of these rooms $65 \%$ overall in Malaysia compared to Indonesia and Thailand which hovers around 45 to $50 \%$ in both countries. However, Singapore remained the main destination with an average of $80 \%$ occupancy rates overall (Langdon \& Ping, 2009).

However, despite the growth and encouraging development of the hotel industry, the industry has faced many challenges. There are many operating issues such as shortage of trained staff and skilled workers, increased operating and overhead costs, fragmented market and marketing, technological challenges like online reservations and of course the most upcoming issue of green hoteling. Many have written on these challenges. Prabhu and Sidhrar (1996) primarily identified operational issues pertaining to hotel industry. The authors pointed out that human resource and scarce good quality workers were missing. There was high turnover of staff. There was also lack of technology to improve and capture customer satisfaction and there was an increasing need to address environmental issues in hoteliers. Blum (1997) argued other issues plaguing the hotel industry, which includes franchise management, higher operating costs like food and genetically altered food, the emergence of eco-tourism and also the problem of sexual harassment in workplace. Jin Zhao et al (2009) recently argued that other issues were emerging. Labour shortages and increase competition was a main problem. Guests were more sophisticated coupled with online reservations and apps that compare prices and provide reviews against these 
hoteliers. There is also emerging issues of terrorism, natural disasters as well as outbreak of pandemic like SARS and H1N1, which altogether affected the occupancy rates, and competitiveness of the industry.

However, two main challenges stand out amidst the modern hoteling industry in Malaysia. Firstly, there is a need to embrace technology and OM must address the issue of harnessing technology to satisfy customers' needs more effectively. Secondly, there is also a need for OM to address the key issues of green hotel and how OM can provide a competitive advantage and a key term to reduce pollution and keeping it at the lowest levels. This paper addresses these two key issues in turn below.

\section{Enhancing Technology as an Operation Competitive Advantage}

Long gone are the days when customers pick up the telephone and dial the hotel to make personal reservation for rooms and stays. Previously, customers are not too sophisticated and have very little opportunity to compare the range of services across different hotels and as well as to read commentaries by other reviewers. One of the main challenge in hotel operators in Malaysia is the shortage of skilled staff that is conversant in communication skills. This is where language barriers become a main obstacle especially with tourists and guests arriving from abroad (Aldohon, 2014).

Many employees in hotel industry lack English proficiency, and the Malaysian Association of Hotels argued that it is more important for staff to be conversant in English rather than having them the ability to converse in diverse languages (Malaysian Association of Hotels, 2013). However, training employees in English is very challenging and takes up much time. Many authors have highlighted on this problem. For example, Wenyuh (2012) indicated that there is a link between language efficiency and quality of service in hotel industry. There is a study in Malaysia (Rao \& Abdullah, 2007) where data collected from major hotels in Langkawi showed that guests perceived the quality of a hotel is connected to staff's language proficiency. However, this study is criticised as it only centered in Langkawi and does not include hotels below the 5-star category.

Nevertheless, the impact of poor language efficiency on the branding and class of the hotel is significant. It has a direct impact on the perception of the guests towards the prestige and branding of the hotel itself. Because retraining the employees to improve language efficiency is time consuming and requires many expenses, many hotels have revamped their operational strategy to include the use of Communication App in their services and interactions with the guests. Communication App is a type of computer or programming device that can run on smaller appliances such as smartphones and tabs. The main aim of using such devices is to boost and increase the efficiency of communication (Wang, 2013). There are already many of these apps in other spheres such as food delivery, museum, tourism, transportation etc. Using and applying these apps in hotel industry can be a useful operational strategy and tactic to improve the brand and prestige of a hotel.

It was suggested that the use of mobile apps especially at the concierge and the restaurants could prove significant values to the guests (Raimond Selke et al., 2015) and helps to migrant to acquire and transfer their knowledge more efficiently. For example, in Shenzhen a company built an App in approximately 100 foreign languages to be used in hotels and restaurants. The result was an increased in customer satisfaction and higher brand perception (Hyun et al., 2009). Mobile Apps is not a new phenomenon. It has been used in many other industries such as the taxi and now infamously Grab and Uber. There are also many Apps for tourists already activated in Tokyo Japan. In Malaysia, Ritz Carlton was the first 5-star hotel that began using Apps in the early 2000s. In that sample, Ritz Carlton pioneered the way by giving guests a hand phone devised with enlisted phone directory as well as mobile calls for room services. This move put Ritz Carlton into the running for the best hotels in Malaysia in 2002. The only drawback was that guests have to use two mobile devices that was cumbersome for the guests (Raimon Selke, 2015). Therefore, the improved version is to use downloadable Apps that could bring virtual reality to booking, checking in and ordering of the hotel's facilities. According to Abukhalifeh and Mat Som (2012) modern Apps are able to provide a virtual reality for the guests and services from the Apps include translating languages, a virtual tour of the hotel and updating food menus and rating the quality of staff services. One good example of this application of Apps is the Hotel Sama - Sama that uses the Ipads and touch screen pads replacing conventional menus. As a result, the occupancy rate of the hotel increased by $15 \%$.

The use of these Apps were crucial as technology are used as an operational tool to reduce language barriers between the staff and the guests. This is useful especially where both parties speak a different language. Another example on the usage of Apps is in Mira Hotel Hong Kong. The hotel operators allowed guests unlimited free Wifi usage and unlimited international calls to 25 popular countries. The data usage powered by a $4 \mathrm{G}$ coverage connected to all ICT within the hotel including booking of facilities etc through the 'My Mira' portal. It also contains other information pertaining to popular local destinations like Disney Land, museum, airport taxis etc. (http://www.themirahotel.com). This App was most welcomed as it increased virtual interactions between the 
guests and the hotel as well as those entertainments centres around the vicinity. Furthermore, the Apps proved useful for those returning guests and the Apps were used strategically to track and trace guests' preferences as well as what they like in the hotel. This has allowed the hotel to track the guests more effectively and as a result, customers' satisfaction was inflated.

However, using Apps as an operational communication tool is not without limitations. Firstly, there are fears that the increased use of internet technology exposes hotels to cyber security risks. Raimond Salke et al (2015) stated that increasing use of internet communication technology (ICT)exposes hotels to cyber-attacks and that would put the details and information of guests especially VIPs at risks. The author also argued that the use of ICT could replace the intimacy of face-to-face communication and retards personal interactions, which is a primary focus in hospitality industry.

\section{The Strategic Values of Green and Sustainability Operation and Management in Hotels}

Sustainability and going green is currently a major concern in hotel industries both locally and globally. Globally many hotels are bogged down by the need to go green and paying more attention to develop sustainable business (Bohdanowicz \& Martinac, 2007). The author argued that approximately $80 \%$ of pollution by hotel industry arise from consuming too much of water, electricity and producing too much waste when operating their businesses. Many hotels are changing and revamping their operations to ensure that the daily operations and management of the premise complies with the green standards. Some of the relevant concerns pertaining to sustainable hoteling include energy consumption, food and beverage management, wastes and recycle products, linen, and upholstery in the hotels. Of course, one of the most prominent issue in green and sustainability concern is energy consumption. Energy consumption is the second largest expenditure in hotels after employment (Arvind et al., 2012). It represents $60 \%$ of $\mathrm{Co} 2$ emissions in hotels. The author argued that energy consumption in hotels are dependent on a variety of factors that include: size of hotel, location, number of facilities provided, the use of technology in hotels, the structural design of the hotel, the age of the hotel as well as the operational hours of the organisation. In general, hotels in hotter climates like Malaysia require more energy consumption and older hotels will consume more energy as the wirings and electrical appliances are old. Furthermore, the increased use of internet of things and communication technologies will also mean an increased consumption of energy. Therefore, it is important that hotels develop operations that are green and sustainable in terms of energy consumption and producing lesser waste. The benefits for hotels to develop greener operation has three major benefits. Firstly, it reduces operation costs. Secondly, it complies with regulatory standards and thirdly it helps to develop invaluable branding of the organisation. For instance, Far Eastern Hotel used melting ice as air conditioner for rooms and other facilities outlet. The air from melting ice replaced the use of air conditioner. It uses about 2,000 tons of ice cubes at night. Moreover, the waste water from swimming pools are used to cool down air conditioning compressors to reduce the use of fresh water which is reserved for other more important facilities. This part of this essay explores the operational tools that hotels can undertake to make their organisations more environmentally compliant.

Many global efforts drive environmental concerns and supporting issues in hotel sustainability management. For example, the Green Hotel Association established in 1993 aimed to create more awareness amongst hoteliers concerning environmental issues (Kong Fang Zheng et al., 2001). Other organisations such as the Green Seal in the USA, Canadian Environmental Choice and the Norwegian Green Management in Practice are some of the notable institutions that drive green awareness amongst hoteliers globally. In 1998, the Tourism Council in Australia encouraged hotelier to provide 'natural' accommodation styles for guests including green produce, green services, facilities and to educate guests on the essentials of environmental protections.

The Green Mountain State in 2006 introduced the term 'Green Hotel'. It encompasses "a hotel that makes efforts on creating a fine environment and encourages its staff and customers to participate in the activity. It also needs to observe carefully each operation to reduce impacts on environment". Green hotel is also defined as "a hotel which saves water and energy in a constructive manner and reduces solid wastes to maintain our environment" (Judy et al., 2007). Another author defined green hotel as "a hotel that evaluates surrounding ecological condition before starting construction and tries not to aggravate impacts on environment" (Erdogan \& Baris' study, 2007).

In summary, green hotel encompasses a holistic approach of operational management in hotels. It includes the building and construction of the building, the management of wastes, energy and educating staff and guests pertaining to these issues. The main contention of green hotel is to instil a fundamental go green attitude, which include revamping operational ideology relating to: (1) recycling products especially management of wastes (2) recycling energy, (3) reduce usage of energy and natural resources in facilities operations and (4) educating and instilling a continuous effort amongst staff and guests to continue go green attitude. 
So the question is how do the re-emphasis on going green in hotels affect the operations of these hoteliers? How do hoteliers revamp their operational strategy to maximise and enjoy the strategic advantages flowing from these operational changes? To answer these questions, one may want to take a quick look at the case study of Far Eastern Plaza Hotel (hereinafter referred to as the FEP) in Taipei to examine how going green has changed the operation of the hotel as well as providing a competitive advantage for the organisation.

FEP was the first organisation awarded with ISI 4000 for environmental standards in 2002. The hotel is also an award winner for going green efforts by the Taiwanese government. FEP placed great emphasis on revamping its operational strategies to achieve the going green efforts as well as to reduce carbon footprints. FEP has now become a pioneer in environmental protection and conservation and is the leader in the industry to have initiated such a practise in Taiwan. To fulfil its going green efforts, FEP initiated a couple of operational changes. Operational energy saving measures include adding water limiter faucets in toilets and bathrooms. They also installed ultra-sensors in staff restrooms to limit the use and flow of water. Toilet flush systems modified to include two-switch flush system. One of the main innovation is to trap and recycle rainwater especially during monsoon periods so that the water could be used to flush and clean hotel premises reducing the use of treated water. The management also rewarded guests that change towels less frequently by giving additional free drinks and tit-bits for their efforts. Leaflets and notes given to staff and guests about the need to safe electricity and resources and guests were fined to food wastage especially on buffet menus. Landscaping lights were automatically dimmed in wee hours and water fountains shut down after midnight to avoid water evaporation.

To boost their going green philosophy, FEP made every effort to instil going green philosophy and culture in the organisation. FEP established clear policies on environmental protection translated into Key Performance Index for their staffs. Employees were rewarded extensively for their contributing efforts to protect the environment. There is also bi annual campaign to clean the nearby beaches as well as planting trees and clearing weeds around neighbouring forests. Guests were also educated for such affairs and are invited to join and participate in the beach cleaning events, which also includes games and food. The response towards these events are intense and received applause from the public as well as the staffs. The effect of these strategic operational changes are enormous and FEP has gained recognition as the pioneer in sustainable hoteling in Taiwan. It won a number of accolades and received further incentives by the Taiwanese government to implement stage 2 of sustainable campaign. It also saved the hotel 6 million annually in terms of lesser water usage, lesser energy consumption as well as lesser food consumption (Chen \& Chen, 2012).

However, whilst there are much advantages of establishing go green operations and management in hotels, there are some pertinent challenges that prevented a full fledge application of these operational strategies in hotels both locally and abroad. A few studies have identified the barriers pertaining to the implementation of green and sustainable operations in Malaysian hotels. Chan (2008) argued that hotels face six different types of barriers when implementing sustainable and green operations. The barriers are lack of knowledge and expertise, costs and expenses in executing the projects, insufficient support from staff and guests, maintenance costs, lack of government support and lack of external certifications in these areas. Vikneswaran Nair et al (2012) stated three more barriers that include lack of urgency and standard guidelines, difficulty in measuring green initiatives and thirdly incoherency of going green as quality services.

\section{Conclusion}

The hotel industry is in a flux. It is changing rapidly. Hotel industry is shifting in line with technological advancement and the need to use ICT to upgrade their communication and peripheral services to the clients. The use of internet of things as well as upgrading communication between staff and guests via more effective software is becoming a necessary trend among the hoteliers. While the use of technology has improved operational excellence within the industry, it has also made hotels more vulnerable to cyber-attacks. This in turn raised the need to boost and upgrade cyber security to protect the details and personal information of guests especially with the legislation of the Personal Data Protection Act in Malaysia. Again, this paper also reviewed the move of hotel industry towards sustainable and going green efforts. Again, there is a large window of opportunity for hotels to usurp this operational change as a competitive advantage against the competitors. This is seen in FEP that has harnessed competitive edge amongst hoteliers in Taipei Taiwan. However, recent research showed that such initiatives are costly which is a main barrier and obstacle against its implementation in Malaysia. Altering operations according to go green standards require major modifications of mind set as well as operational tools and on ground appliances. This is probably out of reach of smaller hotels, which may see this as a major investment. Again, go green efforts are difficult to measure and often takes a long time before one could reap the benefits of such efforts. 


\section{References}

Aldohon, H. (2014). English for specific purposes (ESP) for Jordanian tourist police in their workplace: Needs and problems. International Education Studies, 7(11), 56-67.

Blum, S. C. (1997). Current concerns: a thematic analysis of recent hospitality industry issues. International Journal of Contemporary Hospitality Management, 9(7), 350-361. https://doi.org/10.1108/09596119710191029

Bohdanowicz, P., \& Martinac, I. (2007). Determinants and benchmarking of resource consumption in hotels - Case study of Hilton International and Scandic in Europe. Energy \& Buildings, 39(1), 82-95. https://doi.org/10.1016/j.enbuild.2006.05.005

Chan, E. S. W. (2008). Barriers to EMS in the hotel industry. International Journal of Hospitality Management, 27(2), 187-196. https://doi.org/10.1016/j.ijhm.2007.07.011

Erdogan, N., \& Baris, E. (2007). Environmental protection programs and conservation practices of hotels in Ankara, Turkey. Tourism Management, 28, 604-614. https://doi.org/10.1016/j.tourman.2006.07.003

Green Hotels Association. (2007). What Are Green Hotels. Retrieved from http://www.greenhotels.com/whatare.htm

Green Hotels in the Green Mountain State. (2006). What Is A Green Hotel. Retrieved from http://www.vtgreenhotels.org/whatis.htm

Holcomb, J. L., Upchurch, R. S., \& Okumus, F. (2007). Corporate social responsibility: what are top hotel companies reporting? International journal of contemporary hospitality management, 19(6), 461-475. https://doi.org/10.1108/09596110710775129

Hyun, M., Lee, S., \& Hu, C. (2009). Mobile-mediated virtual experience in tourism: Concept, typology and applications. Journal of Vacation Marketing, 15(2), 149-164. https://doi.org/10.1177/1356766708100904

Jinzhao, W., \& Jing, W. (2009). Issues, challenges, and trends that facing hospitality industry. Management Science and Engineering, 3(4), 53-58.

Kong, F. Z., Zhe, X. H., Fen, H. H., \& Jing, F. Y. (2001). Environmental Management System in the Hotel Industry-Case of Consumers' Acceptance in Taipei Area. Outdoor recreation quarterly journal, 14(4), 1-26.

Langdon, A., \& Ping, S. Y. (2009). Hotel intelligence report. New York: Jones Lang LaSalle Hotelso.

Nair, V., \& Anantharajah, S. (2012). A green makeover for our Hotels. Quartely DOE update on Environment, Development \& Sustainability, 2, 10-12.

Poon, W. C., \& Low, K. L. T. (2005). Are travellers satisfied with Malaysian hotels? International Journal of Contemporary Hospitality Mangement, 17(2/3), 11. https://doi.org/10.1108/09596110510591909

Prabhu, S. (1996). Challenges for hospitality and tourism operators: a North American perspective. International Journal of Contemporary Hospitality Mangement, 8(7), 52-62. https://doi.org/10.1108/09596119610152050

Rao, R., \& Abdullah, S. (2007). The Role of the English Language in the Tourism Industry. Teaching English in Asia 2nd International Conference, Penang, June 2007. Penang.

Tan, A. (2010). 10 hotels in Malaysia now hold Green Award status. The Star. Retrieved December 8, 2017, from http://thestar.com.my/news/

Weaver, D., \& Lauton, L. (2006). Tourism Management. Australia: John Wiley \& Son.

Wenyuh, S. (2012). Hotel Employees' Perception on Their Workplace English Use: An Example from Taiwan. US-China Foreign Language, 10(11), 1729-1733.

Ying, C. C., \& Yu, T. C. (2012). The Advantages of Green Management for Hotel Competitiveness in Taiwan: In the Viewpoint of Senior Hotel Managers. Journal of Management and Sustainability, 2(2). https://doi.org/10.5539/jms.v2n2p211

\section{Copyrights}

Copyright for this article is retained by the author(s), with first publication rights granted to the journal.

This is an open-access article distributed under the terms and conditions of the Creative Commons Attribution license (http://creativecommons.org/licenses/by/4.0/). 